\title{
ENDOVENOUS LASER TREATMENT OF THE SMALL SAPHENOUS VEIN. SINGLE-CENTRE EXPERIENCE STUDY
}

\author{
Piotr Terlecki' ${ }^{1}$, Stanisław Przywara', Marek Iłżecki' , Piotr Kawecki², Tomasz Zubilewicz \\ 'Department of Vascular Surgery and Angiology, Medical University of Lublin, Poland \\ 2Department of Radiology, $1^{\text {st }}$ Military Clinical Hospital in Lublin, Poland
}

\begin{abstract}
Objectives: Endovenous laser treatment of incompetent great saphenous vein is widely described in the literature. Only a few studies, mainly with a limited number of patients and a short follow up are related to minimally invasive laser ablation of small saphenous vein. Our paper presents single centre experience of 140 small saphenous vein laser ablations with long term postoperative follow up.

Material and methods: The group of patients who underwent endovenous laser treatment of small saphenous vein consisted of 132 patients. Totally, 140 small saphenous vein laser ablations were performed (in some patients bilaterally). The endovenous laser ablation was carried out using the VenaCure diode laser, $1470 \mathrm{~nm}$ - AngioDynamics, Never Touch Fibre.

Results: We achieved very high efficacy of the procedure with $100 \%$ primary occlusion rate. Postoperative rate of significant complications was markedly low and included only 2 deep vein thromboses (1.4\%), 2 late, spontaneous recanalizations (1.4\%) and transient paresthesias did not exceed $9.8 \%$ (13 patients). Frequency of minor typical side effects of the procedure as ecchymoses and bruising $(8.4 \%)$ and micropuncture site hematomas (23\%) was typical for endovenous laser treatment procedures. Conclusions: Endovenous laser treatment of small saphenous vein insufficiency is safe, quick, requires only a few hours of hospitalisation and provides very good cosmetic effect, quick recovery and fast return to normal activities. In opinion of authors the method seems to be advantageous to open surgery of short saphenous vein.
\end{abstract}

Key words: small saphenous vein, endovenous laser treatment, chronic venous disease.

\author{
ORIGINAL PAPER \\ Phlebological Review 2014; 22, 1: 6-10 \\ DOI: $10.5114 /$ pr.2014.46047
}

Submitted: 23.06 .2014

Accepted: 30.06 .2014

\section{ADDRESS FOR CORRESPONDENCE: \\ Stanisław Przywara, Department of Vascular Surgery and Angiology, \\ Medical University of Lublin, \\ Staszica 11 Street, 20-081 Lublin, Poland, \\ e-mail: s.przywara@plusnet.pl}


Table 1. Preoperative patients' demographics

\begin{tabular}{lc}
\hline Parameter & Number (range) \\
\hline Numbers of patients & 132 \\
\hline Numbers of treated limbs & 140 \\
\hline Mean age in years (range) & $42(19-71)$ \\
\hline Gender (M/F) & $27 / 105$ \\
\hline Mean SSV diameter in mm (range) & $6(4-9)$ \\
\hline
\end{tabular}

Table 2. CEAP classification

\begin{tabular}{lc}
\hline CEAP Classification & Number (\%) \\
\hline C2 & $108(82 \%)$ \\
\hline C4 & $18(13 \%)$ \\
\hline C5 & $6(5 \%)$ \\
\hline
\end{tabular}

\section{MATERIAL AND METHODS}

In the years 2009-2013 we performed more than 2500 procedures of laser ablation of insufficient great saphenous veins and small saphenous veins. The group of patients who underwent endovenous laser treatment of small saphenous veins consisted of 132 patients. In total, 140 small saphenous vein laser ablations were performed (in some patients bilaterally). Of these patients, 105 were female and 27 were men. Average age was 42 years. The demography and patient characteristics are shown in Table 1.

All of the patients in this group presented clinical symptoms of chronic venous disease related to small saphenous vein insufficiency, with varicose veins, significantly affecting their quality of life in terms of physical wellbeing and aesthetic issues. The staging of the chronic venous disease in this group of patients according to CEAP classification is shown in Table 2. Patients were qualified for EVLT treatment based on the results of colour Doppler ultrasound, which was performed in the

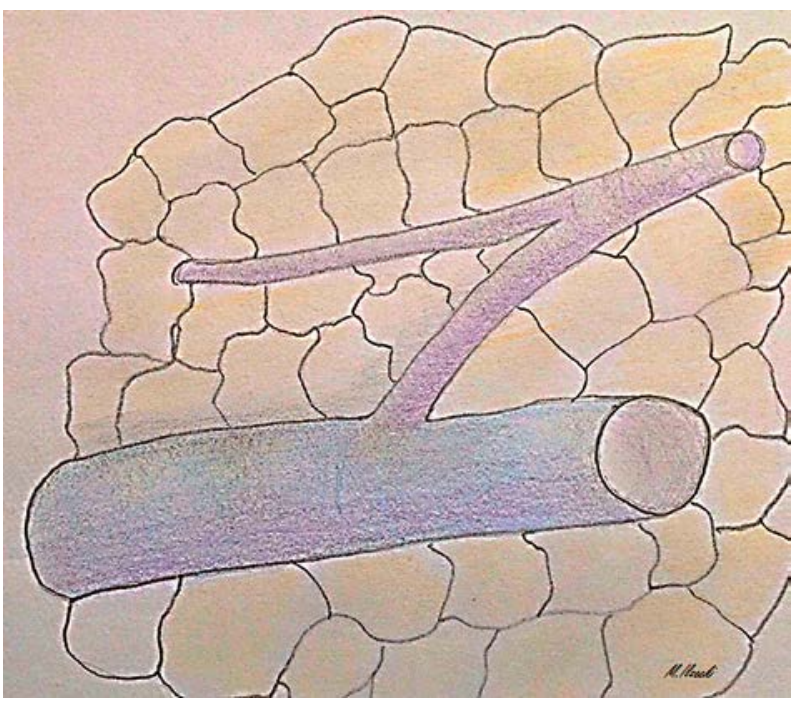

Fig. 2. Small saphenous vein - popliteal vein junction - type 2

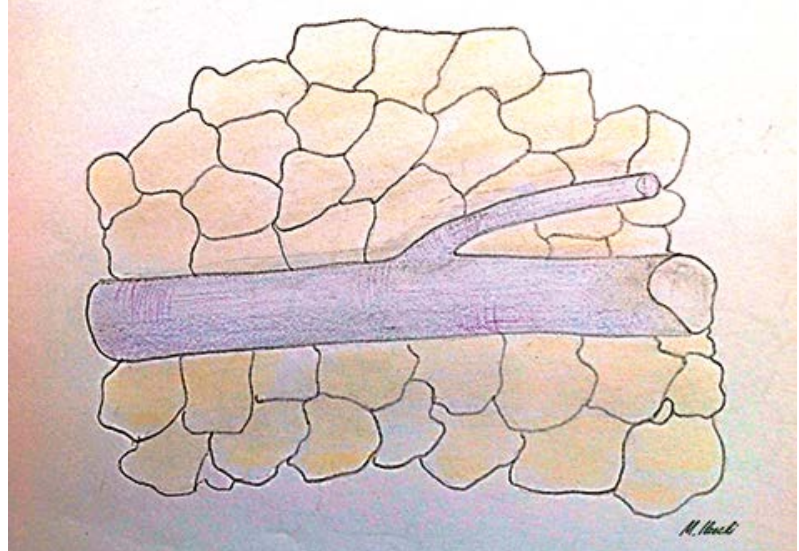

Fig. 1. Small saphenous vein - popliteal vein junction - type 1

standing position and revealed valvular insufficiency of the small saphenous vein and its saphenopopliteal junction. Based on ultrasound examination three anatomical types of small saphenopopliteal junction were distinguished: type 1 - direct junction of small saphenous vein with popliteal vein; type 2 - tributary Giacomini vein branching from small saphenous vein before its junction with popliteal vein; and type 3 - high junction of small saphenous vein with deep veins of the thigh. These anatomical variations of small saphenous vein junction with deep venous system are, in the opinion of the authors, crucial during preoperative planning of the procedure and are shown on Figs. 1, 2, and 3 (illustrations $\odot$ Marek Itżecki).

The diameter of the small saphenous vein was on average $6 \mathrm{~mm}$ (range 4-9 $\mathrm{mm}$ ).

\section{Procedure description}

All patients were hospitalised as one-day admissions. The procedure was performed with the patient a prone position.

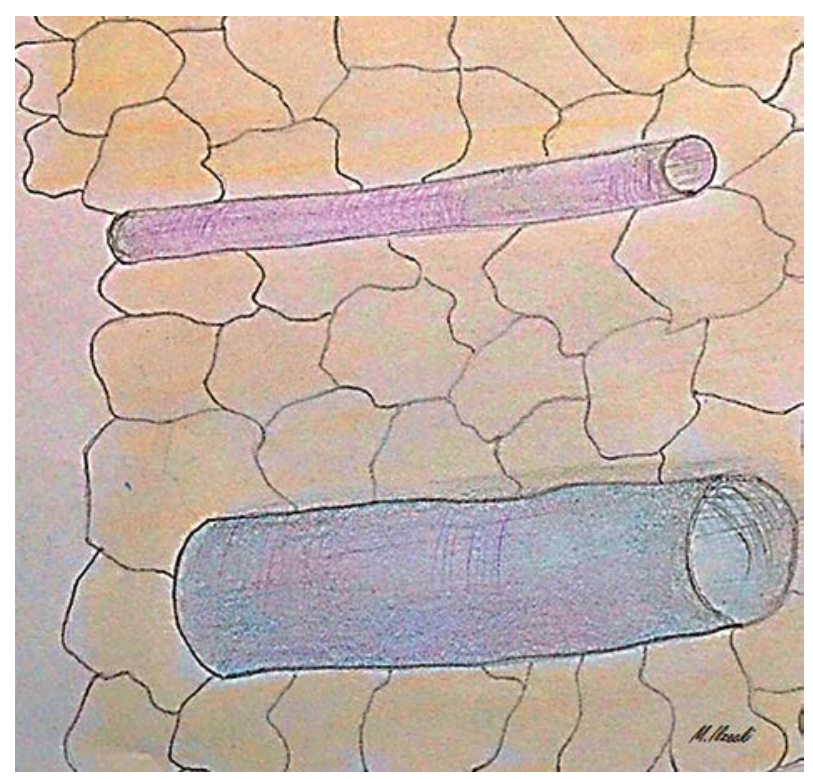

Fig. 3. Small saphenous vein - popliteal vein junction - type 3 
The small saphenous vein was punctured in the middle segment under ultrasound control. Then, under ultrasound guidance, a guidewire and $4 \mathrm{~F}$ sheath were advanced in the proximity of the junction with the popliteal vein. The guidewire was exchanged for a laser fibre via the sheath. The laser fibre tip was located $2 \mathrm{~cm}$ below the small saphenous-popliteal vein junction, which was confirmed by ultrasound. In case of the presence of Giacomini vein tributing to small saphenous vein, the laser fibre tip was positioned below the ostium of the Giacomini vein. Local tumescent anaesthesia was performed with $0.1 \%$ lignocaine in an average dose of $14 \mathrm{ml} / \mathrm{cm}$. The anatomical and functional accuracy of tumescence was continuously controlled by ultrasound. In two patients allergic to lignocaine, bupivacaine in adequate concentrations was used.

The endovenous laser ablation was carried out using a VenaCure diode laser, $1470 \mathrm{~nm}$ - AngioDynamics, Never Touch Fibre. The small saphenous vein was ablated with a continuous wave of 6-12 W, retraction speed $4-5 \mathrm{~mm} /$ second, and total energy (linear endovascular energy density - LEED) 50-70 J/cm. Mean surgery duration time was 20 minutes. Patients were mobilised $15 \mathrm{~min}$ utes after the procedure and discharged home two hours later. Antithrombotic prophylaxis with low molecular weight heparin (Enoxaparin $1 \times 40 \mathrm{mg}$ subcutaneously) was applied for a period of 10 days. Standard prophylax-

Table 3. Operative data

\begin{tabular}{lc}
\hline Parameter (units) & Average (range) \\
\hline Laser power (W) & $9(6-12)$ \\
\hline LEED $(\mathrm{J} / \mathrm{cm})$ & $50-70$ \\
\hline Tumescence $(\mathrm{ml} / \mathrm{cm})$ & $14(12-20)$ \\
\hline Procedure time (min) & $20(18-30)$ \\
\hline Postoperative closure rate & $100 \%$ \\
\hline Compression stockings & $100 \%$ \\
\hline LMWH prophylaxis & $100 \%$ \\
\hline
\end{tabular}

Table 4. Follow up data

\begin{tabular}{lc}
\hline Observation time in months & 36 \\
\hline Pain duration in days: average (range) & $4(1-6)$ \\
\hline Analgesia need in days: average (range) & $6(4-8)$ \\
\hline Ecchymosis: number (\%) & $11(8.4 \%)$ \\
\hline Paraesthesia: number (\%) & $13(9.8 \%)$ \\
\hline Hematoma: number (\%) & $30(23 \%)$ \\
\hline DVT: number (\%) & $2(1.4 \%)$ \\
\hline PE: number (\%) & $0(0 \%)$ \\
\hline SSV recanalisation: number (\%) & $2(1.4 \%)$ \\
\hline Recovery time in days: average (range) & $4(2-6)$ \\
\hline
\end{tabular}

is with low molecular weight heparin was applied due to our experience with occasional, spontaneous occurrence of deep vein thrombosis in our much larger material with EVLT treatment of insufficient long saphenous vein. Second class compression therapy with stockings was administered during 7 days for 24 hours continuously, and then for 30 days only during the day. Technical parameters and other significant data related to the procedure are presented in Table 3.

A total of 118 patients underwent the foam sclerotherapy of varicose veins just after laser ablation (1\% Aethoxysclerol) or four weeks after the procedure, as a complementary treatment. None of the patients required mini-phlebectomy. Postoperative ultrasound control visits were carried out within 24 hours (postoperatively), 7 days, 30 days, 6 months, 12 months, and 24 months after surgery. The longest follow up was 36 months.

\section{RESULTS}

Endovenous laser treatment of insufficient small saphenous vein was performed in 132 patients. In total, 140 small saphenous veins were ablated (some patients underwent bilateral ablation). Primary success rate was achieved in 132 patients (100\%). Postoperative control ultrasound examination confirmed the occlusion of the vein in all cases. Two patients (1.4\%) developed deep vein thrombosis (DVT) in the femoral-popliteal segment, without clinical symptoms of pulmonary embolism (PE). Standard treatment with low molecular weight heparin and oral anticoagulant or rivaroxaban alone was introduced. Ecchymoses and bruising along the anatomical course of small saphenous vein were observed in 11 patients (8.4\%). Transient paraesthesias related to thermal exposure of sural nerve were reported by 13 patients $(9.8 \%)$. The most common side effects of the procedure were small haematomas in the site of micropuncture of small saphenous veins, which were observed in 30 patients (23\%). These regressed spontaneously. On average, patients suffered from local pain for four days after ablation and required small doses of oral pain killers for six days. During the follow up period recanalisation of the vein occurred only in two patients (1.4\%). Endovenous laser re-ablation performed in these patients after six months was successful. The average time of return to normal daily activities, including professional ones, was four days. Repeated sclerotherapy of recurrent varicose veins was needed in $2.8 \%$ of patients ( 4 cases) during the follow-up period. Follow-up data are presented in Table 4.

\section{DISCUSSION}

The treatment of superficial venous insufficiency has changed in the last decade. Conventional surgery for small saphenous vein incompetence results in a high incidence of recurrence (up to $52 \%$ at 3 years) and is frequently associated with neurovascular injury [8]. 
In many instances this is the result of inaccurate ligation of saphenopopliteal junction. Even in experienced hands, saphenopopliteal ligation is not always technically successful.

This is mainly due to the diverse anatomic anomalies of the saphenopopliteal junction and its proximity to the tibial and sural nerves [9].

The small saphenous vein lies in close relationship with surrounding nerves. Above the popliteal fossa the thigh extension of the small saphenous vein is in contact with the posterior femoral nerve (small sciatic nerve). In the popliteal fossa the termination of the small saphenous vein can be in contact with tibial or common peroneal nerves. When the small saphenous vein ends above the popliteal skin crease and is displaced laterally, the risk of nerve injury is increased. Below the popliteal crease, the sural nerve can join the small saphenous vein at a variable level, and at the ankle the nerve is always in contact with the small saphenous vein and may be wrapped around it [10].

Many complications of surgical stripping of the small saphenous vein have been described, along with damage to the sural nerve, the tibial nerve, and the common peroneal nerve $[11,12]$.

Ligation, with or without surgical stripping of insufficient saphenous veins has mostly been replaced by thermal and non-thermal endovenous therapies, due to their superior efficacy and less invasive character [13].

Results of EVLT for small saphenous vein insufficiency have repeatedly been described, with short-term occlusion rates ranging from $91 \%$ to $100 \%[14,15]$.

Chaar found that veins measuring $>1 \mathrm{~cm}$ could be successfully treated with EVLT, with no increase in failure or complication rates, despite more energy being used for treatment. The routine use of tumescent analgesia in EVLT and RFA reduces the diameter of the veins by mechanical compression and vasospasm from the cold temperature of the tumescent solution. This provides better contact and approximation of the wall of the vein to the probe and optimal dissipation of energy [16].

Previous publications have suggested that larger veins may be associated with higher failure of EVLT in the great saphenous vein and the small saphenous vein. Kontothanassis et al. excluded small saphenous veins measuring $>13 \mathrm{~mm}$ from treatment with EVLT. They divided the veins treated into three categories based on size, with the largest veins being 9-13 $\mathrm{mm}$ in diameter [17].

Desmyttere et al. published the results of EVLT in 511 limbs and reported a success rate of $97 \%$ after four years of follow-up. They noted that all the failures occurred in larger veins $(>8 \mathrm{~mm})$, but no statistical analysis was performed [18].

In our experience, the long-term occlusion rate reached nearly $100 \%$, and only two patients required re-ablation.

Published literature contains conflicting rates of postoperative nerve injury following endovenous laser ablation of the small saphenous vein. Some studies report frequen- cies as high as $40 \%$. The principal hypothesis of this study was that puncturing the small saphenous vein at the most distal point may increase post-operative nerve injury due to the close relationship between the small saphenous vein and the sural nerve at the level of the ankle [19].

Theivacumar et al. reported 3 temporary paraesthesia in a group of 65 patients with small saphenous vein incompetence [20]. However, Desmytte're et al. reported $40 \%$ temporary paraesthesia in a 147-patient series [21].

When these conflicting results were analysed, in Theivacumar's study the cannulation site was mid-calf or higher. They used a $810 \mathrm{~nm}$ diode laser, $12 \mathrm{~W}$ laser energy, and a LEED of $60-72 \mathrm{~J} / \mathrm{cm}$. In the Desmytte're group, they cannulated the small saphenous veins from mid-to-lower calf. A $980 \mathrm{~nm}$ laser, $10 \mathrm{~W}$ energy, and various LEEDs $(50-90 \mathrm{~J} / \mathrm{cm})$ were used. Although Desmytte're's group used less energy (10 W vs. $12 \mathrm{~W}$ ) and a higher wavelength (980 $\mathrm{nm}$ vs. $810 \mathrm{~nm}$ ), their paraesthesia results were dramatically higher than reported in Theivacumar's study. In Desmytte're's group, there is no subgroup analysis to assess at which LEED the paraesthesia rate is increased. The main difference seems to be the puncture levels.

From previous experience with the $1470 \mathrm{~nm}$ laser and radial fibre, Doganci et al. predicted a $30 \%$ paraesthesia rate in the malleolar cannulation group compare to $6 \%$ using the mid-calf cannulation site, lasting two months in the first group and two weeks in the second group [22].

Persistent numbness is reported in $1.3-4.4 \%$ of cases $[23,24]$.

We observed paraesthesias in $9.8 \%$ of patients. The relatively low rate of this specific complication seems to be related to the site of puncture of the small saphenous vein that we chose - always in the middle segment of the vein. Average LEED in our group was 50-70 J/cm, and continuous laser energy was on average $9 \mathrm{~W}$, thus lower values were used than these presented in Desmytte're's group.

Serious complications following EVLT are uncommon. Pulmonary emboli are extremely rare, with only one literature report found. Extension of a clot into deep veins has been noted by many investigators, with an incidence of $0-5.7 \%$ for the small saphenous vein. In our study we observed two cases (1.4\%) of deep vein thrombosis at the femoral-popliteal level with mild severity of symptoms. The variability in the observation of deep vein thrombus is likely accounted for by different techniques, learning curve, the sensitivity of the equipment used to detect the thrombus, and the time interval between EVLT and imaging to look for thrombus. In most cases DVT is due to other risk factors such as deficiency of protein $\mathrm{C}$ and $\mathrm{S}$, mutation of factor $\mathrm{V}$, or long-term oestrogen therapy $[25,26]$.

Many studies describe the incidence of bruising and discomfort following EVLT, but it causes significantly less post-procedural discomfort and bruising compared to traditional surgical therapies. There are no clinically significant infections except for erythema at the access site 
treated with oral antibiotics and steroids. There is one literature report of a phlegmonous infection of a limb treated with surgical drainage and antibiotics [27].

\section{CONCLUSIONS}

Endovenous laser treatment of the small saphenous vein is safe and effective. Low rate of complications, oneday hospitalisation, short recovery time, and quick return to professional activities makes this method, in our opinion, advantageous to open surgery.

\section{References}

1. Beebe-Dimmer J., Pfeifer J., Engle J., Schottenfeld D. The Epidemiology of Chronic Venous Insufficiency and Varicose Veins. Ann Epidemiol 2005; 15: 175-184.

2. Van den Bos R., Arends L., Kockaert M., Neumann M., Nijsten T. Endovenous therapies of lower extremity varicosities: a metaanalysis. J Vasc Surg 2009; 49: 230-239.

3. Van Den Bos R.R., Neumann M., De Roos K.P., Nijsten T. Endovenous laser ablationinduced complications: review of the literature and new cases. Dermatol Surg 2009; 35: 1206-1214.

4. Gloviczki P., Comerota A.J., Dalsing M.C., Eklof B.G., Gillespie D.L., Gloviczki M.L., Lohr J.M., McLafferty R.B., Meissner M.H., Murad M.H., Padberg FT, Pappas P.J., Passman M.A., Raffetto J.D., Vasquez M.A., Wakefield T.W.; Society for Vascular Surgery; American Venous Forum. The care of patients with varicose veins and associated chronic venous diseases: clinical practice guidelines of the Society for Vascular Surgery and the American Venous Forum. J Vasc Surg 2011; 53 (5 suppl): 2S-48S.

5. Samuel N., Wallace T., Carradice D., Shahin Y., Mazari F.A., Chetter I.C. Endovenous laser ablation in the treatment of small saphenous varicose veins: does site of access influence early outcomes. Vasc Endovascular Surg 2012; 46: 310-314.

6. Monahan T.S., Belek K., Sarkar R. Results of radiofrequency ablation of the small saphenous vein in the supine position. Vasc Endovascular Surg 2012; 46: 40-44.

7. Kontothanassis D., Di Mitri R., Ferrari Ruffino S., Zambrini E., Camporese G., Gerard J.L., Labropoulos N. Endovenous laser treatment of the small saphenous vein. J Vasc Surg 2009; 49: 973-979.

8. van Rij A.M., Jiang P., Solomon C., Christie R.A., Hill G.B. Recurrence after varicose vein surgery: a prospective long-term clinical study with duplex ultrasound scanning and air plethysmography. J Vasc Surg 2003; 38: 935-943.

9. Huisman L.C., Bruins R.M., van den Berg M., Hissink R.J. Endovenouslaser ablation of the small saphenous vein: prospective analysis of 150 patients, a cohort study. Eur J Vasc Endovasc Surg 2009; 38: 199-202.

10. Gerard J.L. Small saphenous vein ablation: particularities and precautions. In: Controversies and updates in vascular surgery. Becquemin J.P., Alimi Y.S., Gerard J.L. (eds.). Edizioni Panminerva Medica, Torino 2009; 450-454.

11. Atkin G.K., Round T., Vattipally V.R., Das S.K. Common peroneal nerve injury as a complication of short saphenous vein surgery. Phlebology 2007; 22: 3-7.

12. van Groenendael L., Flinkenflögel L., van der Vliet J.A., Roovers E.A., van Sterkenburg S.M., Reijnen M.M. Conventional surgery and endovenous laser ablation of recurrent varicose veins of the small saphenous vein: a retrospective clinical comparison and assessment of patient satisfaction. Phlebology 2010; 25: 151-157.

13. Tellings S.S., Ceulen R.P., Sommer A. Surgery and endovenous techniques for the treatment of small saphenous varicose veins: a review of the literature. Phlebology 2011; 26: 179-184.

14. Theivacumar N.S., Beale R.J., Mavor A.I., Gough M.J. Initial experience in endovenous laser ablation (EVLA) of varicose veins due to small saphenous vein reflux. Eur J Vasc Endovasc Surg 2007; 33: 614-618.

15. Ravi R., Rodriguez-Lopez J.A., Trayler E.A., Barret D.A., Ramaiah V., Diethrich E.B. Endovenous ablation of incompetent saphenousveins: a large single-centre experience. J Endovasc Ther 2006; 13: 244-248.

16. Chaar C.I., Hirsch S.A., Cwenar M.T., Rhee R.Y., Chaer R.A., Abu Hamad G., Dillavou E.D. Expanding the role of endovenous laser therapy: results in large diameter saphenous, small saphenous, and anterior accessory veins. Ann Vasc Surg 2011; 25: 656-661.

17. Kontothanassis D., Di Mitri R., Ferrari Ruffino S., Zambrini E., Camporese G., Gerard J.L., Labropoulos N. Endovenous laser treatment of the small saphenous vein. J Vasc Surg 2009; 49: 973-979.

18. Desmyttere J., Grard C., Wassmer B., Mordon S. Endovenous 980-nm laser treatment of saphenous veins in a series of 500 patients. J Vasc Surg 2007; 46: 1242-1247.

19. O'Hare J.L., Vandenbroeck C.P., Whitman B., Campbell B., Heather B.P., Earnshaw J.J., Joint Vascular Research Group. A prospective evaluation of the outcome after small saphenous varicose vein surgery with one-year follow-up. J Vasc Surg 2008; 48: 669-673.

20. Theivacumar N.S., Beale R.J., Mavor A.I., Gough M.J. Initial experience in endovenous laser ablation (EVLA) of varicose veins due to small saphenous vein reflux. Eur J Vasc Endovasc Surg 2007; 33: 614-618.

21. Desmytte're J., Grard C., Stalnikiewicz G., Wassmer B., Mordon S. Endovenous laser ablation $(980 \mathrm{~nm})$ of the small saphenous veinin a series of 147 limbs with a 3-year follow-up. Eur J Vasc Endovasc Surg 2010; 39: 99-103.

22. Doganci S., Yildirim V., Demirkilic U. Does puncture site affect the rate of nerve injuries following endovenous laser ablation of the small saphenous veins? Eur J Vasc Endovasc Surg 2011; 41: 400-405.

23. Theivacumar N.S., Beale R.J., Mavor A.I., Gough M.J. Initial experience in endovenous laser ablation (EVLA) of varicose veins due to small saphenous vein reflux. Eur J Vasc Endovasc Surg 2007; 33: 614-618.

24. Huisman L.C., Bruins R.M., van den Berg M., Hissink R.J. Endovenous laser ablation of the small saphenous vein: prospective analysis of 150 patients, a cohort study. Eur J Vasc Endovasc Surg 2009; 38: 199-202.

25. Proebstle T.M., Gul D., Kargl A., Knop J. Endovenous laser treatment of the lesser saphenous vein with a $940-\mathrm{nm}$ diode laser: early results. Dermatol Surg 2003; 29: 357-361.

26. Ravi R., Rodriguez-Lopez J.A., Traylor E.A., Barrett D.A., Ramaiah V., Diethrich E.B. Endovenous ablation of incompetent saphenous veins: a large single-center experience. J Endovasc Ther 2006; 13: 244-248.

27. Dunst K.M., Huemer G.M.,Wayand W., Shamiyeh A. Diffuse phlegmonous phlebitis after endovenous laser treatment of the greater saphenous vein. J Vasc Surg 2006; 43: 1056-1058. 